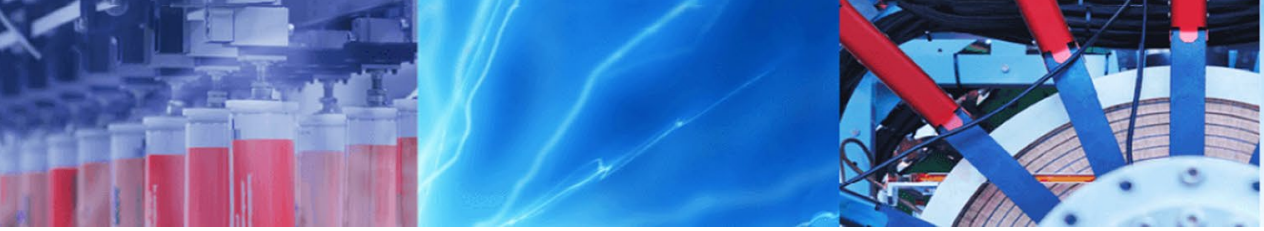

Research Article

\title{
Fabrication of cobalt filled multi-walled carbon nanotubes/ polyurethane composite for microwave absorption
}

\author{
Navdeep Singh ${ }^{1} \cdot$ Gagan Deep Aul ${ }^{1}$ (I)
}

Received: 14 February 2020 / Accepted: 23 October 2020 / Published online: 20 November 2020

(c) Springer Nature Switzerland AG 2020

\begin{abstract}
This research work describes the design and method of development of microwave absorber. This study was conducted for analysis of reflection loss performance with the magnetic modifications of Multi-Walled Carbon Nanotubes (MWCNTs). Cobalt filled Multi-Walled Carbon Nanotubes composites were prepared by three step method. Composites were developed with varying weight percentage of Cobalt Sulphate and Multi-Walled Carbon Nanotubes. The morphology, elementary analysis and absorbing properties of Cobalt filled Multi-Walled Carbon Nanotubes composites were studied by FESEM, EDX and Vector Network Analyzer. The maximum reflection loss is observed for ( $50 \%$ MWCNT and $50 \%$ Cobalt Sulphate) is $-30.22 \mathrm{~dB}$ at $11.8 \mathrm{GHz}$ and the maximum bandwidth window is available for ( $40 \%$ MWCNT and $60 \%$ Cobalt Sulphate) is $3.9 \mathrm{GHz}$ in the frequency range of $8-13 \mathrm{GHz}$ with $3 \mathrm{~mm}$ thickness, which can be credited to synergistic effect of improved matched impedance and greater microwave attenuation properties of the absorber. The combined usage of dielectric loss and magnetic loss absorber design shows great diversity and can be a promising candidate for designing high performance microwave absorbing materials.
\end{abstract}

Keywords Multi-walled carbon nanotubes (MWCNTs) - Wet chemical method · Microwave absorption · Reflection loss

\section{Introduction}

Radar detection reduction technique protects an airplane against radar cross section (RCS) detection which becomes vital in modern high-performance combat technology equipments. RCS can be reduced by altering the shapes of airplanes, radar absorbing materials (RAM). The aim of shaping is to alter the system designs to reduce RCS but shaping has some limitation from the view of manufacturing industry because they cannot compromise with system designs just for the sake of RCS reduction. Despite of this, the developers may coat delicate parts of the target with Radar Absorbing Material. The Radar Absorbing Materials are developed to absorb electromagnetic waves so as to reduce the reflected waves and RCS reduction [1]. Magnetic or dielectric particles are essentially used for the microwave absorption materials. Magnetic or metal particles have high relative gravity and challenging construction which constrained their real-world applications. Therefore, there is a requirement for an effective electromagnetic wave absorbing material which should be costeffective, flexible, lightweight and efficient in absorption in a wide range of frequencies. Nanoparticles composites have great fascination for fabrication of electromagnetic wave absorbing materials in a wide frequency spectrum due to their various exceptional chemical, physical and electrical characteristics. The unique properties and an excellent structure of carbon nanotubes (CNTs) causes extensive studies for many prospective EMI shielding applications [2-4]. Carbon nanotubes (CNTs) are assembled by carbon atoms with covalent bonding between carbon-carbon atoms, are nano scale structures [5].

Gagan Deep Aul, gaganaul79@gmail.com | 'Department of Electronics and Communication Engineering, DAV University, Jalandhar, Punjab 144012, India. 
CNTs are discovered by lijima in 1991. Since its discovery, CNTs have become the main focus of analyzers all over the world because of its incredible physical properties due to strong atomic bonding. Carbon nanotubes are categorized into two categories, Single-Walled Carbon Nanotubes (SWCNTs) and Multi-Walled Carbon Nanotubes (MWCNTs). CNTs also have high electric conductivity which enhances electromagnetic wave absorption [6-10]. Ferromagnetically modified CNTs have gained intensive attention towards the microwave absorbing performance of nanocomposites.

Many researches had endeavored to encapsulate the CNTs with ferromagnetic material. Encapsulations of ferromagnetic materials like $\mathrm{Co}, \mathrm{Ni}, \mathrm{Fe}$ and $\mathrm{Zn}$ in the CNTs are greatly fascinating nanostructure materials with magnetic and dielectric properties. There are some analysis reported on MWCNTs with different composite materials which depicts the microwave absorption properties of the composites [11-15]. Jie Sun et al. prepared a copper cobalt nickel ferrite/graphene oxide/polyaniline tri-composite and investigated in the frequency range of 2-18 GHz. When the usage of tri-composite is about $40 \%$, it has a maximum reflection loss of $-33 \mathrm{~dB}$ at $10.8 \mathrm{GHz}$ with $2 \mathrm{~mm}$ thickness [16]. Qilei Wu et al. synthesized the cobalt doped porous carbon composite with a low-dielectric amorphous carbon/Zn shell shows maximum reflection loss of $-43.97 \mathrm{~dB}$ at $10.86 \mathrm{GHz}$ with absorption bandwidth of $4.1 \mathrm{GHz}$ [17]. Pei-Yan Zhao et al. fabricated Ni/MWCNTs composites with $20 \mathrm{wt} \%$ fillers shows reflection loss of $-46.85 \mathrm{~dB}$ at $6.56 \mathrm{GHz}$ with $3.2 \mathrm{GHz}$ bandwidth and $3.7 \mathrm{~mm}$ thickness in frequency range of $2-18 \mathrm{GHz}$ [18]. Wei Chen et al. manufactured the double-layered composites and characterized in $\mathrm{X}$-band. The maximum reflection loss of double-layered composites is $-45.7 \mathrm{~dB}$ with $4.2 \mathrm{GHz}$ bandwidth and $1.8 \mathrm{~mm}$ thickness [19]. Yiru Li et al. fabricated the Ni/MWCNTs hybrid structure showed the minimum RL of Ni/MWCNTs (20 wt\%) hybrids was $-40.65 \mathrm{~dB}$ at $11.2 \mathrm{GHz}$ with $3.6 \mathrm{GHz}$ bandwidth and $1.8 \mathrm{~mm}$ thickness in $2-18 \mathrm{GHz}$ frequency range [20]. Zhen-Jie Guan et al. constructed the sandwich-like cobalt/reduced graphene oxide/cobalt composites showed maximum reflection loss was $-61 \mathrm{~dB}$ at 11.1 GHz with $4 \mathrm{GHz}$ bandwidth and $2 \mathrm{~mm}$ thickness in 2-18 GHz frequency range [21]. Mei Wu et al. synthesized the Graphene oxide/CNT/Co $\mathrm{Fe}_{3-\mathrm{x}} \mathrm{O}_{4}(\mathrm{x}=0.375)$ ternary nanocomposites has reflection loss value of $-71.3 \mathrm{~dB}$ with the bandwidth of $2.52 \mathrm{GHz}$ and thickness of $7.92 \mathrm{~mm}$ in 2-18 GHz frequency range [22]. Xiaogang Su et al. investigated the $\mathrm{CoFe}_{2} \mathrm{O}_{4} / \mathrm{FeCo} / \mathrm{Graphite}$ hybrid composites at filling ratio of $50 \mathrm{wt} \%$ showed, maximum reflection loss of $-54.3 \mathrm{~dB}$ at $1.2 \mathrm{~mm}$ thickness and $4.08 \mathrm{GHz}$ bandwidth at $1.3 \mathrm{~mm}$ thickness in $2-18 \mathrm{GHz}$ frequency range [23]. Zhen Xiang et al. synthesized the $\mathrm{Y}^{-} \mathrm{Fe}_{2} \mathrm{O}_{3}$ /MWCNTs hollow nanosphere composites with a filling ratio of $20 \mathrm{wt} \%$ achieved reflection loss of $-63.6 \mathrm{~dB}$ at $1.4 \mathrm{~mm}$ thickness and $5.2 \mathrm{GHz}$ bandwidth in $2-18 \mathrm{GHz}$ frequency range [24]. Li Peibo et al. prepared the Co/C (70\%), Ba-hexaferrite (29\%), MWCNTs (1\%) composites shows maximum reflection loss was $-26 \mathrm{~dB}$ at $12.4 \mathrm{GHz}$ with $4.2 \mathrm{GHz}$ bandwidth and $2.5 \mathrm{~mm}$ thickness in the $X$ band [25].

The main objective of this work was to exhibit an easiest procedure for the fabrication of Cobalt filled MWCNTs/Polyurethane composites for microwave absorption. During filling of Cobalt in MWCNTs, the nitrogen atmosphere was required. Nitrogen gas was fed into flasks through syringe needle which was connected with syringe and then balloons. Main principle of this work was to fill the magnetic nanoparticles into the MWCNTs and to study material characteristics i.e. morphology and elemental analysis of nanocomposites. Then Polyurethane was added to Co/MWCNTs nanocomposites, to made the samples harder and to study electrical characteristics i.e. reflection loss performance in the frequency range of $8-13 \mathrm{GHz}$.

\section{Experiment}

\subsection{Materials}

The MWCNTs with 5-20 nm diameter, 2-10 $\mu$ m length, less than $2 \%$ ash contents, more than $97 \%$ purity, high thermal and electric conductivity were purchased from Aritech Chemazone PVT. LTD., Kurukshetra, Haryana. Nitric Acid (68\% concentration), Cobalt (II) Sulphate, $N, N$-Dimethylformamide (DMF), Polyurethane (PU) were purchased from $A$ Kay Scientific Store, Jalandhar, Punjab.

\subsection{Synthesis of composites}

\subsubsection{Functionalization of MWCNTs}

MWCNTs were heated in nitric acid (68\%) using water bath refluxer upto $100^{\circ} \mathrm{C}$ for $7 \mathrm{~h}$ to remove trace impurities. Refluxed mixture was filtered with distilled water using Suction Pump filtration until pH 7. Further it was then dried at $50^{\circ} \mathrm{C}$ in hot air oven for $12 \mathrm{~h}$ results in functionalized MWCNTs [26-33]. Functionalized MWCNTs were filled with cobalt by wet-chemical method [34] with two different experimental analysis, in which first one includes the varying composition proportion of functionalized MWCNTs and Cobalt Sulphate while the other one includes the varying weight percentage of Cobalt Sulphate solution to develop Cobalt filled MWCNTs nanoparticles composites (Fig. 1). 
Fig. 1 Functionalization of MWCNTs

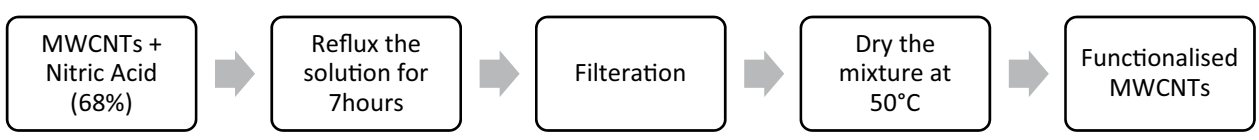

Table 1 Details of varying weight compositions of MWCNTs and Cobalt Sulphate

\begin{tabular}{lll}
\hline Sample code & MWCNT (\%) & $\begin{array}{l}\text { Cobalt Sul- } \\
\text { phate } \mathrm{CoSO}_{4} \\
(\%)\end{array}$ \\
\hline A & 40 & 60 \\
B & 50 & 50 \\
C & 60 & 40 \\
D & 70 & 30 \\
\hline
\end{tabular}

\subsubsection{Analysis 1}

In this analysis, MWCNTs were filled with cobalt after successfully functionalization of MWCNTs. Disperse MWCNTs and Cobalt Sulphate of different weight composition in $1000 \mathrm{ml}$ distilled water using magnetic stirrer for $24 \mathrm{~h}$ as shown in Table 1. The mixture was filtered and rinsed with distilled water using Suction Pump filtration and dried at $45^{\circ} \mathrm{C}$ in hot air oven for $15 \mathrm{~h}$. Then, dried samples were heated for $1 \mathrm{~h}$ under the nitrogen atmosphere, by rising its temperature from room temperature to $100^{\circ} \mathrm{C}$ using sand bath on hot plate. Then, samples were calcinated for $6 \mathrm{~h}$ under the nitrogen atmosphere from room temperature to $450{ }^{\circ} \mathrm{C}$ to reduce the metal oxides by the use of muffle furnace (Fig. 2).

\subsubsection{Analysis 2}

In this analysis, MWCNTs were filled with varying percentage composition of Cobalt Sulphate solution after successfully functionalization of MWCNTs. The functionalized MWCNTs were stirred with $\mathrm{CoSO}_{4}$ solution (varying wt\%) in $200 \mathrm{ml}$ distilled water using magnetic stirrer for $24 \mathrm{~h}$ as shown in Table 2. The mixture was filtered and rinsed with distilled water using Suction Pump filtration and dried at $45^{\circ} \mathrm{C}$ in hot air oven for $15 \mathrm{~h}$. Then, dried samples were heated by rising its temperature from room temperature to $100{ }^{\circ} \mathrm{C}$ for $1 \mathrm{~h}$ under the nitrogen atmosphere using sand bath on hot plate. Then, samples were calcinated from room temperature to $450{ }^{\circ} \mathrm{C}$ for $6 \mathrm{~h}$ under the nitrogen atmosphere to reduce the metal oxides by the use of muffle furnace (Fig. 3).

\subsubsection{Preparation of cobalt filled MWCNT/PU composites}

Cobalt filled MWCNTs composites prepared in analysis 1 and 2 were dispersed in $N, N$-Dimethylformamide (DMF) for $6 \mathrm{~h}$ using ultra sonication. Then, Polyurethane (PU) were dissolved in DMF in another beaker using magnetic stirring for $6 \mathrm{~h}$. The dispersed MWCNTs and PU were mixed thoroughly using magnetic stirrer for next $6 \mathrm{~h}$ [35-37]. The solutions were dried in vacuum oven at $3 \mathrm{kPa}(22.5 \mathrm{~mm}$ of $\mathrm{Hg}$ ) for next $6 \mathrm{~h}$ until gel formation and then poured into WR-90 waveguide mould of dimensions $22.86 \mathrm{~mm}$ (length) $\times 10.16 \mathrm{~mm}$ (width) $\times 3 \mathrm{~mm}$ (thickness) and dried at $35^{\circ} \mathrm{C}$ for $20 \mathrm{~h}$ in hot air oven (Fig. 4).

Table 2 Details of varying compositions of MWCNTs and Cobalt Sulphate

\begin{tabular}{lll}
\hline Sample code & MWCNT $(\mathrm{mg})$ & $\begin{array}{l}\text { Cobalt Sul- } \\
\text { phate } \mathrm{CoSO}_{4} \\
(\%)\end{array}$ \\
\hline $\mathrm{P}$ & 600 & 30 \\
$\mathrm{Q}$ & 500 & 40 \\
$\mathrm{R}$ & 400 & 50 \\
$\mathrm{~S}$ & 300 & 60 \\
\hline
\end{tabular}

Fig. 2 Cobalt filled MWCNTs for Analysis 1

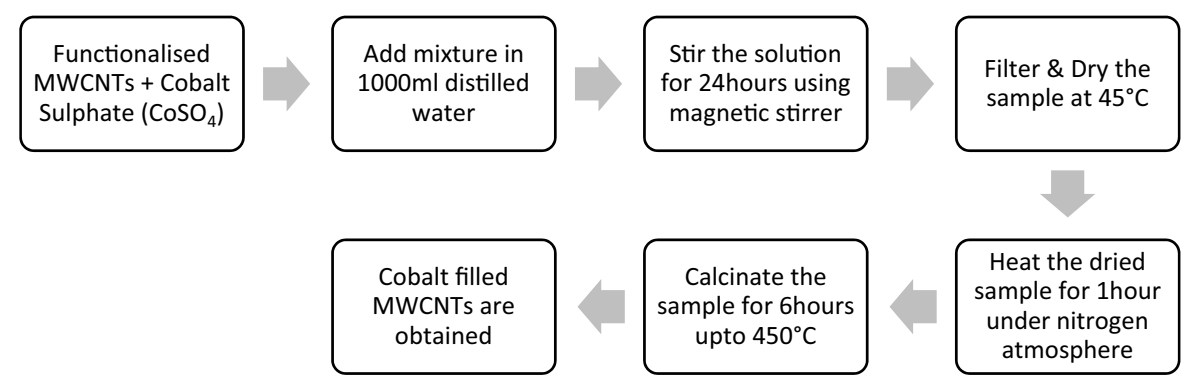

SN Applied Sciences A SPRINGER NATURE journal. 
Fig. 3 Cobalt filled MWCNTs for Analysis 2

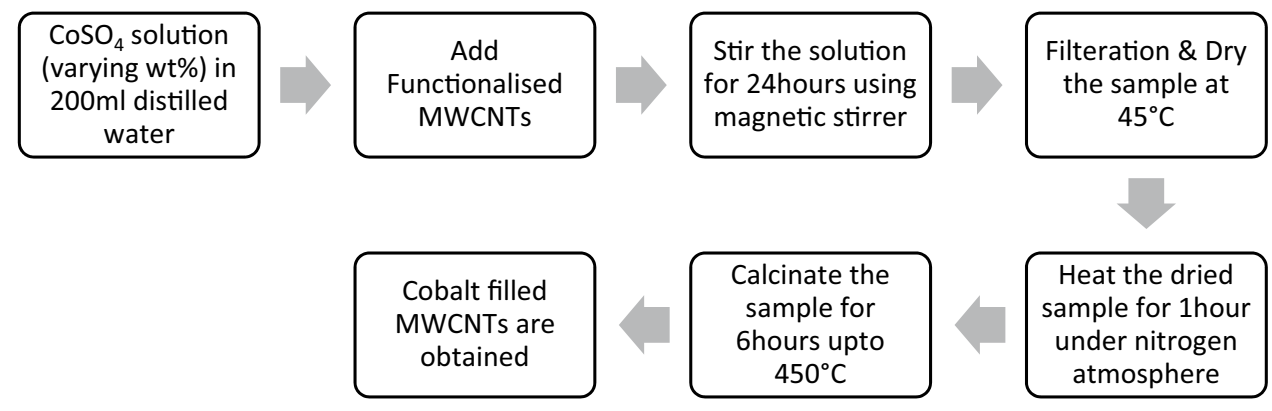

Fig. 4 Cobalt filled MWCNT/PU composites

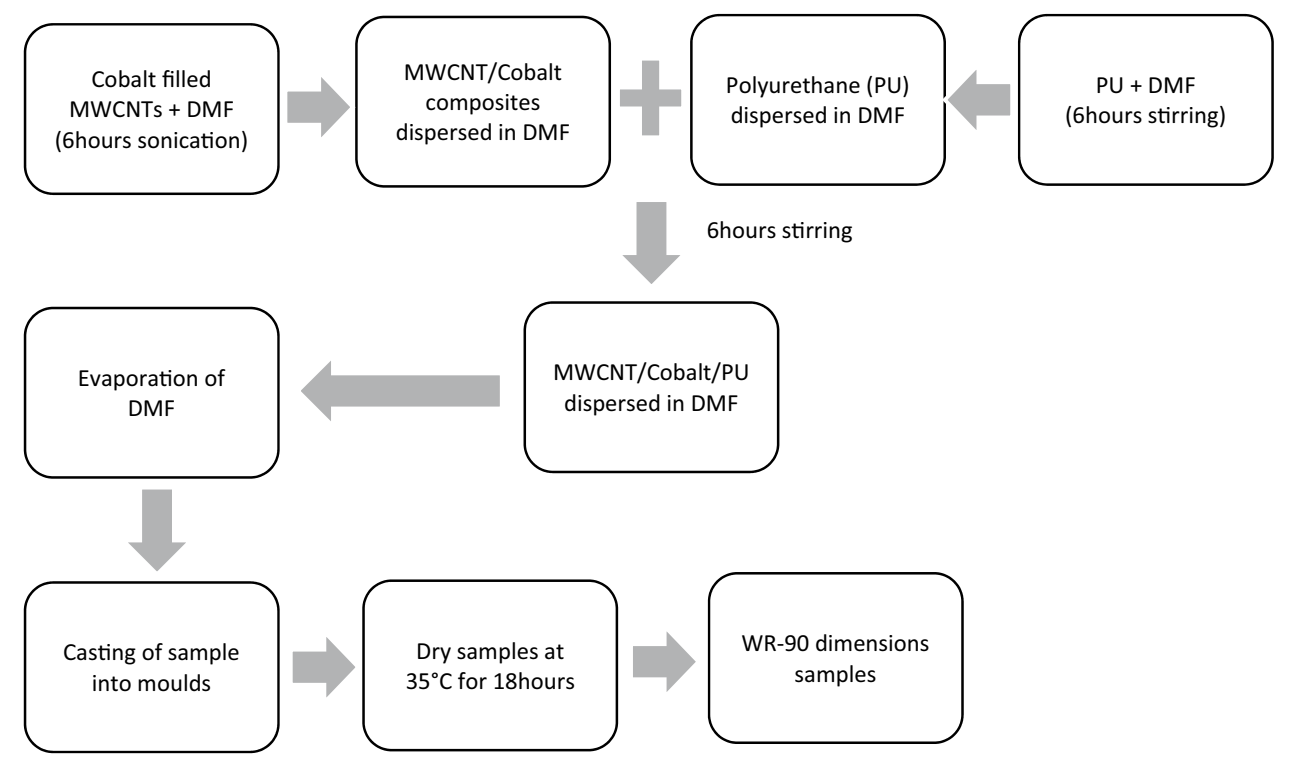

\section{Results and discussion}

\subsection{Morphology and elemental analysis of cobalt filled MWCNTs composites (analysis 1 )}

Field emission scanning electron microscopy (FESEM) was used to understand the morphology of the nanocomposites. Raw MWCNTs are tubular in structure with the diameter of 5-20 nm, 2-10 $\mu \mathrm{m}$ length. While Functionalized MWCNTs have suspended bonds which were created the after acid treatment of MWCNTs. MWCNTs were functionalized to break Carbon-Carbon bonds of MWCNTs and to form $\mathrm{C}-\mathrm{OH}$ or $\mathrm{C}-\mathrm{OOH}$ bonds, which were used for further chemical treatments to bond other elements with MWCNTs.

Sample A has $60 \%$ Cobalt Sulphate and $40 \%$ MWCNT. Figure 5 a shows the morphology of MWCNT filled with Cobalt. In Fig. 5a each nanotube contains denser cobalt nanoparticles due to high percentage contents of cobalt as compared to MWCNTs. Figure 6a shows the EDX spectrum and Fig. $6 \mathrm{~b}$ shows the element analysis, element percentage and atomic percentage of elements present in sample A, which contains Carbon and Cobalt nanoparticles but there are some other impurities are also available i.e. Oxygen, Sodium, Silicon, and Chlorine. Sample A have impurities of Oxygen which arise due to the oxides impurities entrapped in nanoparticles even after the flow of nitrogen gas through them. Sample A have impurities of Silicon due to silicon crucible used for calcination of samples. Sample A have impurities of Sodium and Chlorine due to unwanted impurities present in laboratory, but due to their low weight percentage it doesn't much affects the microwave absorption performance. Sample B has 50\% Cobalt Sulphate and $50 \%$ MWCNT. Figure $5 \mathrm{~b}$ shows the morphology of MWCNT filled with Cobalt. In Fig. 5b there is a homogeneous matrix of MWCNTs and Cobalt nanoparticles due to same percentage composition of Cobalt and MWCNTs nanoparticles. Figure 7 a shows the EDX spectrum and Fig. $7 \mathrm{~b}$ shows the element analysis, element percentage and atomic percentage of elements present in sample B which contains Carbon and Cobalt nanoparticles but there are some impurities of Oxygen, Silicon, Chlorine and Iron which arise during the during chemical reactions processes and testing of material in laboratory. 

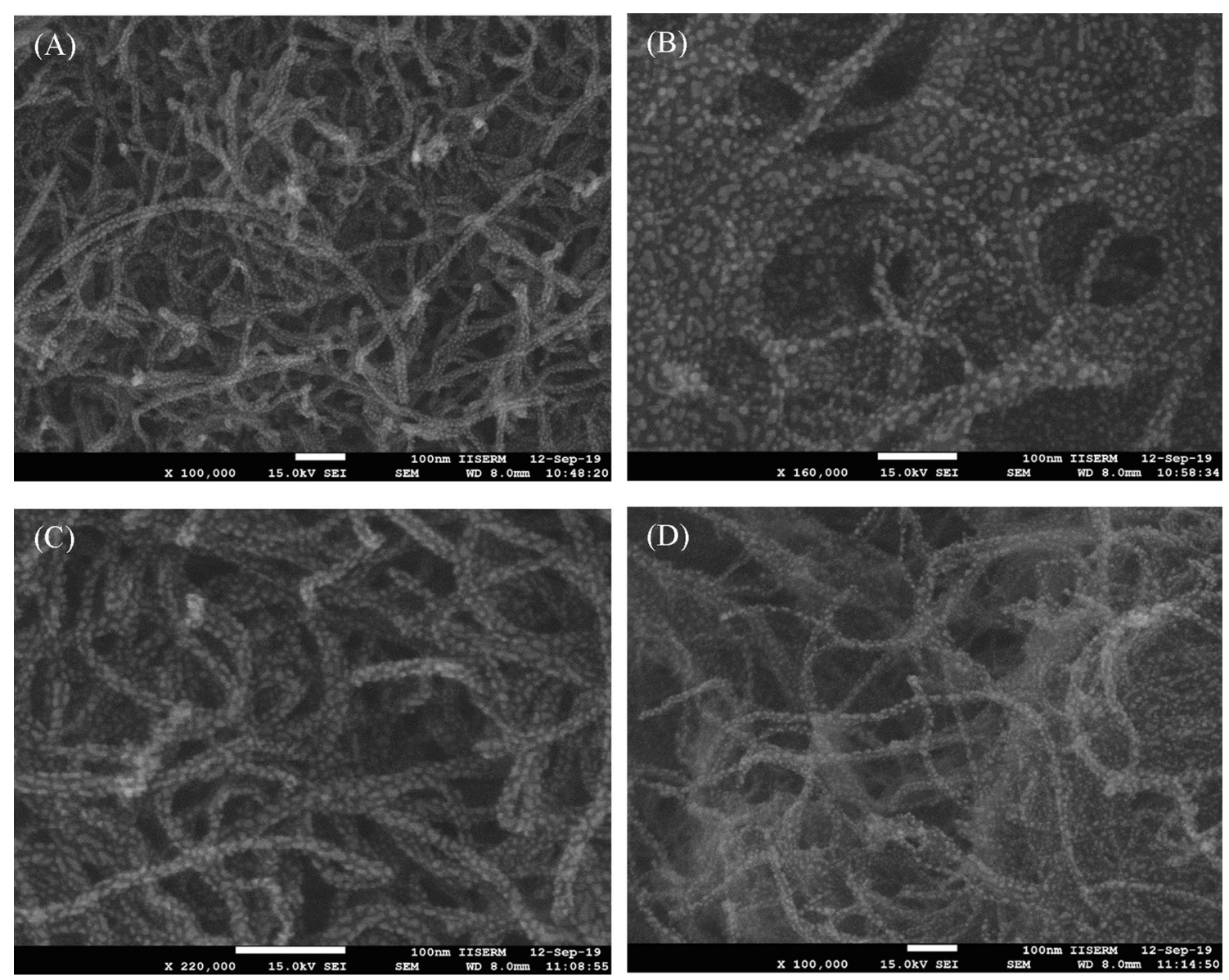

Fig. 5 FESEM of Analysis 1: (a) Sample A (b) Sample B (c) Sample C (d) Sample D

(A)

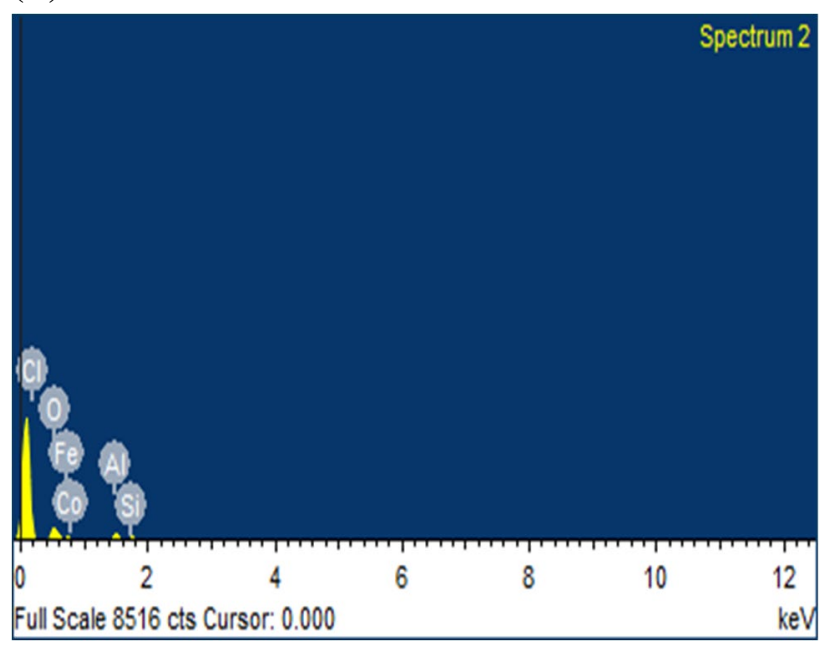

(B)

\begin{tabular}{|c|c|c|}
\hline Element & Weight\% & Atomic\% \\
\hline $\mathrm{C}$ & 5.91 & 14.22 \\
\hline $\mathrm{O}$ & 25.33 & 45.78 \\
\hline $\mathrm{Na}$ & 3.50 & 4.40 \\
\hline $\mathrm{Si}$ & 1.72 & 1.77 \\
\hline $\mathrm{Cl}$ & 3.07 & 2.50 \\
\hline $\mathrm{Co}$ & 60.48 & 31.32 \\
\hline Total & 100.00 & \\
\hline
\end{tabular}

Fig. 6 (a) EDX Spectrum of Sample A (b) EDX composition of Sample A 
(A)

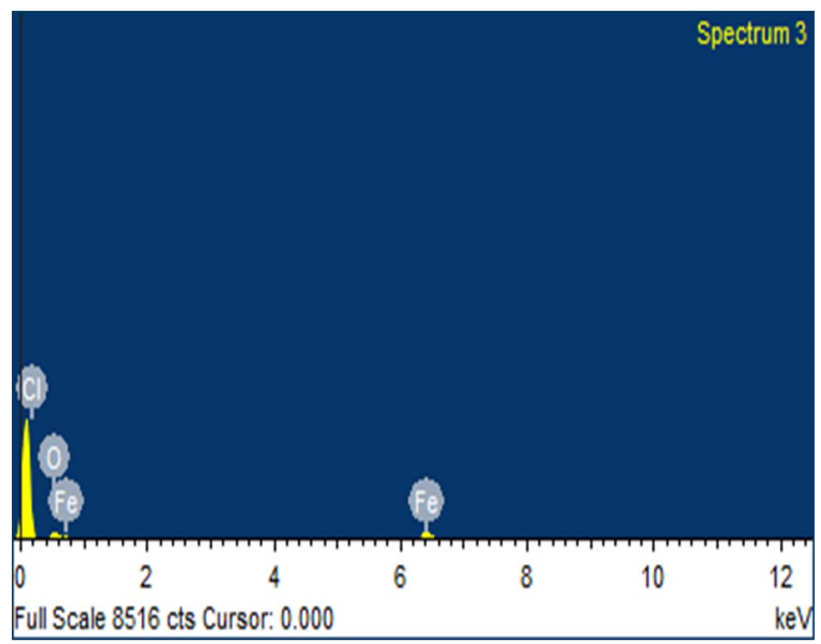

(B)

\begin{tabular}{|c|c|c|}
\hline Element & Weight\% & Atomic\% \\
\hline $\mathrm{C}$ & 15.23 & 25.01 \\
\hline $\mathrm{O}$ & 44.31 & 54.60 \\
\hline $\mathrm{Si}$ & 3.79 & 2.66 \\
\hline $\mathrm{Cl}$ & 2.21 & 1.23 \\
\hline $\mathrm{Fe}$ & 14.74 & 5.20 \\
\hline $\mathrm{Co}$ & 19.72 & 11.30 \\
\hline Total & 100.00 & \\
\hline
\end{tabular}

Fig. 7 (a) EDX Spectrum of Sample B (b) EDX composition of Sample B

(A)

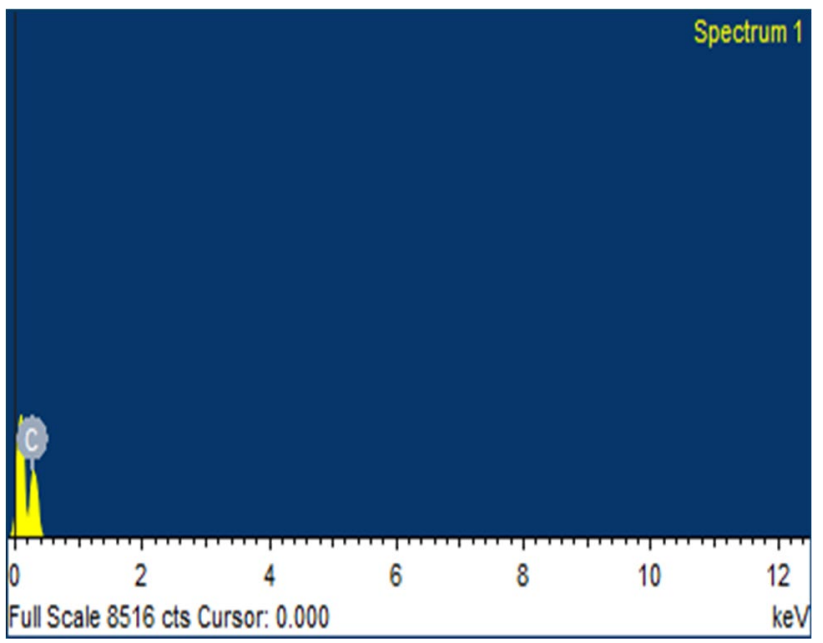

(B)

\begin{tabular}{|c|c|c|}
\hline Element & Weight\% & Atomic\% \\
\hline $\mathrm{C}$ & 67.28 & 69.29 \\
\hline $\mathrm{Si}$ & 0.84 & 0.32 \\
\hline $\mathrm{Co}$ & 32.72 & 30.71 \\
\hline Total & 100.00 & \\
\hline
\end{tabular}

Fig. 8 (a) EDX Spectrum of Sample C (b) EDX composition of Sample C

Sample C has $40 \%$ Cobalt Sulphate and $60 \%$ MWCNT. Figure $5 c$ shows the morphology of MWCNT filled with Cobalt. In Fig. 5c, there is lesser number of cobalt nanoparticles present in each carbon nanotube as compared to the morphology of Fig. $5 a$, b. Figure 8 a shows the EDX spectrum and Fig. $8 \mathrm{~b}$ shows the element analysis, element percentage and atomic percentage of elements present in sample $C$ which contains Carbon and Cobalt nanoparticles with Silicon impurity. Sample D has 30\% Cobalt Sulphate and $70 \%$ MWCNT. Figure $5 \mathrm{~d}$ shows the morphology of MWCNT filled with Cobalt. In Fig. 5d, there is least number of cobalt nanoparticles present in each carbon nanotube as compared to the morphology of Fig. 5a-c. Figure 9a shows the EDX spectrum and Fig. $9 \mathrm{~b}$ shows the element analysis, element percentage and atomic percentage of elements present in sample B which contains Carbon and Cobalt nanoparticles with Aluminium impurity which arise during the during chemical reactions processes.

\subsection{Morphology and elemental analysis of cobalt filled MWCNTs composites (analysis 2)}

Sample P has 30\% Cobalt Sulphate and $600 \mathrm{mg}$ MWCNT. Figure 10a shows the morphology of MWCNT filled with Cobalt. In Fig. 10a each nanotube contains cobalt 
(A)

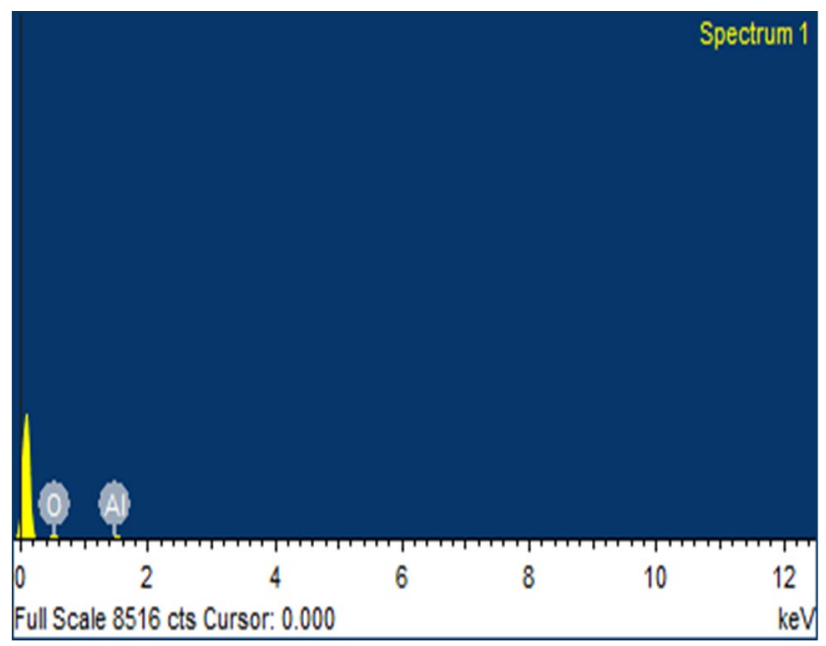

(B)

\begin{tabular}{|c|c|c|}
\hline Element & Weight\% & Atomic\% \\
\hline C & 43.02 & 47.73 \\
\hline O & 28.74 & 35.93 \\
\hline $\mathrm{Al}$ & 7.95 & 7.53 \\
\hline Co & 20.29 & 8.81 \\
\hline Total & 100.00 & \\
\hline
\end{tabular}

Fig. 9 (a) EDX Spectrum of Sample D (b) EDX composition of Sample D
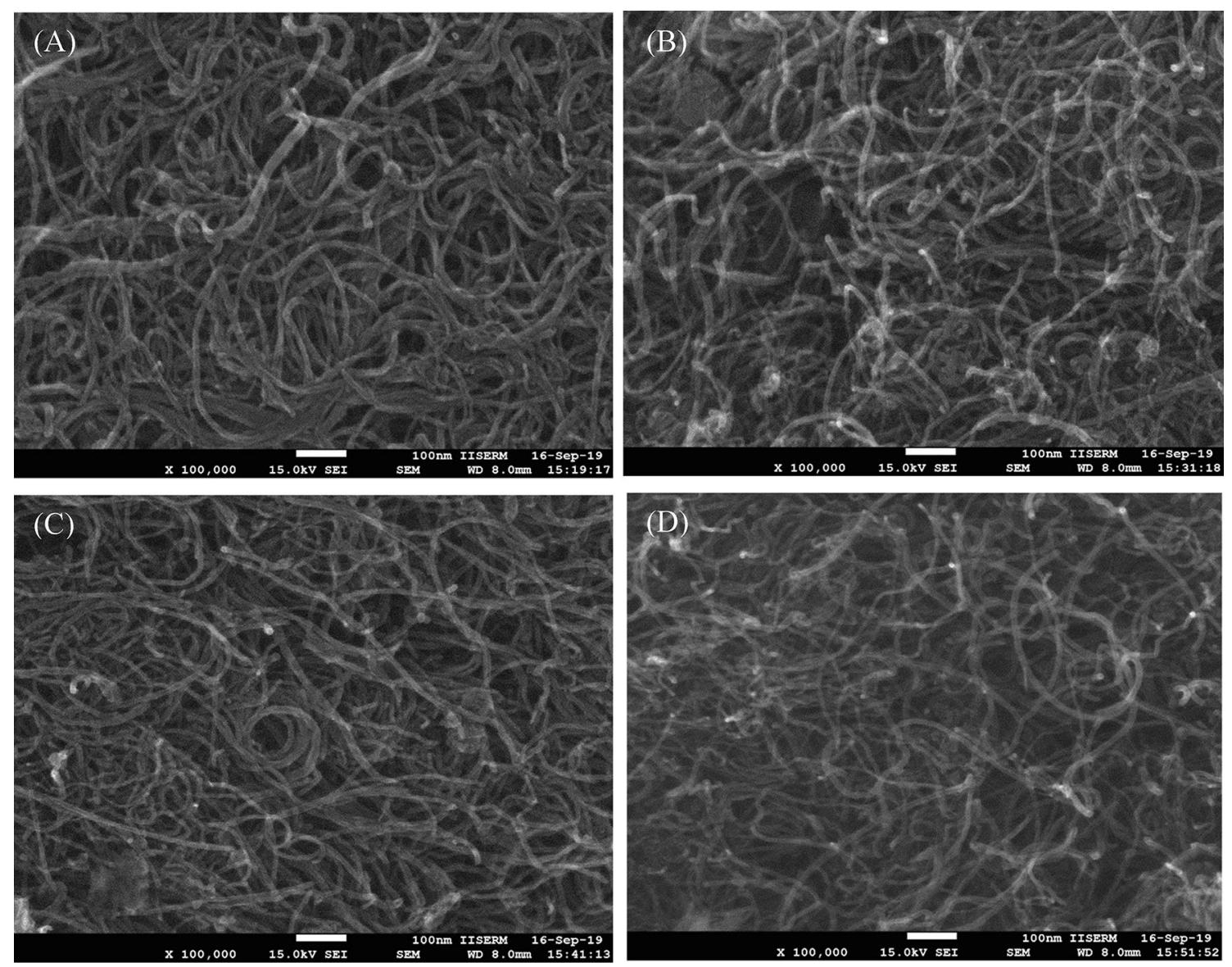

Fig. 10 FESEM of Analysis 2: (a) Sample P (b) Sample Q (c) Sample R (d) Sample S 
(A)

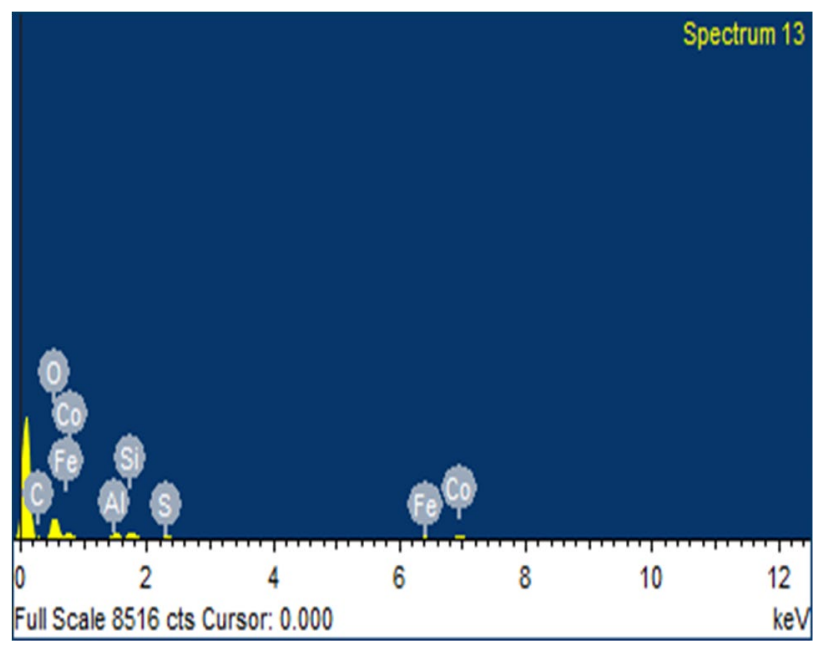

(B)

\begin{tabular}{|c|c|c|}
\hline Element & Weight\% & Atomic\% \\
\hline $\mathrm{C}$ & 12.75 & 23.40 \\
\hline $\mathrm{O}$ & 38.98 & 53.71 \\
\hline $\mathrm{Al}$ & 4.42 & 3.61 \\
\hline $\mathrm{Si}$ & 5.01 & 3.93 \\
\hline $\mathrm{S}$ & 1.89 & 1.30 \\
\hline $\mathrm{Fe}$ & 6.38 & 1.49 \\
\hline $\mathrm{Co}$ & 30.56 & 12.56 \\
\hline Total & 100.00 & \\
\hline
\end{tabular}

Fig. 11 (a) EDX Spectrum of Sample P (b) EDX composition of Sample P

nanoparticles. Figure 11 a shows the EDX spectrum and Fig. $11 \mathrm{~b}$ shows the element analysis, element percentage and atomic percentage of elements present in sample $\mathrm{P}$, which contains Carbon and Cobalt nanoparticles but there are some other impurities are also available i.e. Oxygen, Aluminium, Silicon, Sulphur and Iron. Sample P have impurities of Sulphur due to dispersion of Cobalt Sulphate solution into MWCNTs and on filtration some contents left behind in the Cobalt/MWCNTs nanocomposites, but due to their low weight percentage it doesn't much affects the microwave absorption performance. Sample Q has $40 \%$ Cobalt Sulphate and $500 \mathrm{mg}$ MWCNT. Figure 10b shows the morphology of MWCNT filled with Cobalt. Figure 12a shows the EDX spectrum and Fig. 12b shows the element analysis, element percentage and atomic percentage of elements present in sample $Q$, which contains Carbon and Cobalt nanoparticles and Oxygen due to oxides atom entrapped in MWCNTs. Sample R has 50\% Cobalt Sulphate and $400 \mathrm{mg}$ MWCNT. Figure 10c shows the morphology of MWCNT filled with Cobalt. Figure 13a shows the EDX spectrum and Fig. 13b shows the element analysis, element percentage and atomic percentage of elements present in sample $\mathrm{R}$, which contains Carbon and Cobalt nanoparticles but there are some other impurities are also available i.e. Oxygen, Aluminium, Silicon, and Iron. Impurities like Aluminium, Iron arise during the during chemical
(A)

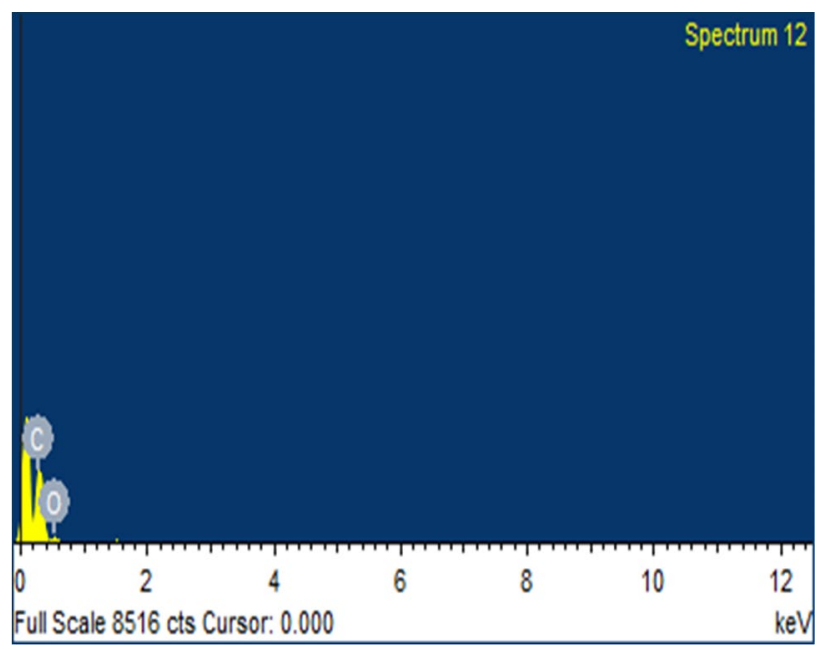

(B)

\begin{tabular}{|c|c|c|}
\hline Element & Weight\% & Atomic\% \\
\hline C & 53.53 & 56.10 \\
\hline O & 4.11 & 3.17 \\
\hline Co & 42.36 & 40.73 \\
\hline Total & 100.00 & \\
\hline
\end{tabular}

Fig. 12 (a) EDX Spectrum of Sample Q (b) EDX composition of Sample Q

\section{SN Applied Sciences}


(A)

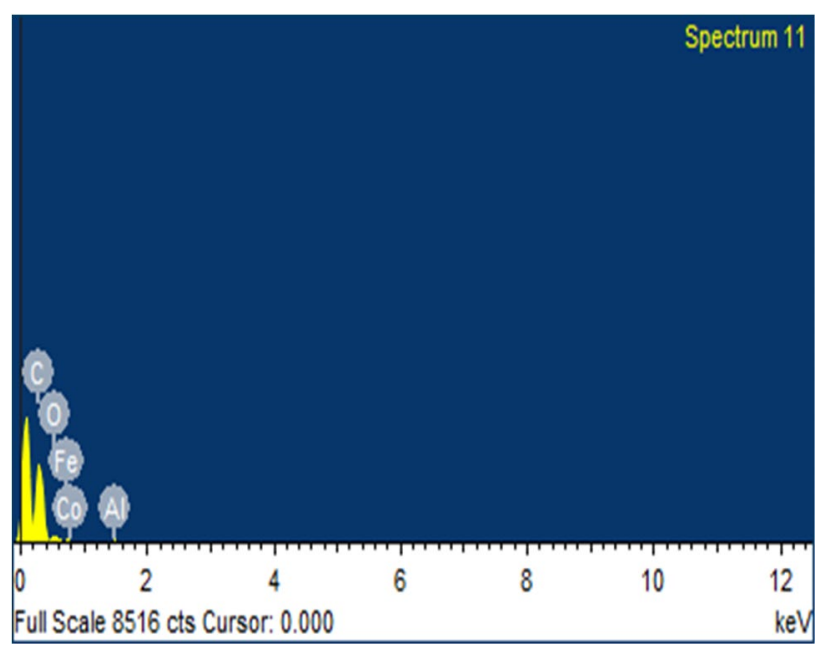

(B)

\begin{tabular}{|c|c|c|}
\hline Element & Weight\% & Atomic\% \\
\hline $\mathrm{C}$ & 40.19 & 44.71 \\
\hline $\mathrm{O}$ & 5.03 & 3.97 \\
\hline $\mathrm{Al}$ & 0.65 & 0.30 \\
\hline $\mathrm{Si}$ & 0.50 & 0.23 \\
\hline $\mathrm{Fe}$ & 1.79 & 0.40 \\
\hline $\mathrm{Co}$ & 51.84 & 50.39 \\
\hline Total & 100.00 & \\
\hline
\end{tabular}

Fig. 13 (a) EDX Spectrum of Sample R (b) EDX composition of Sample R

(A)

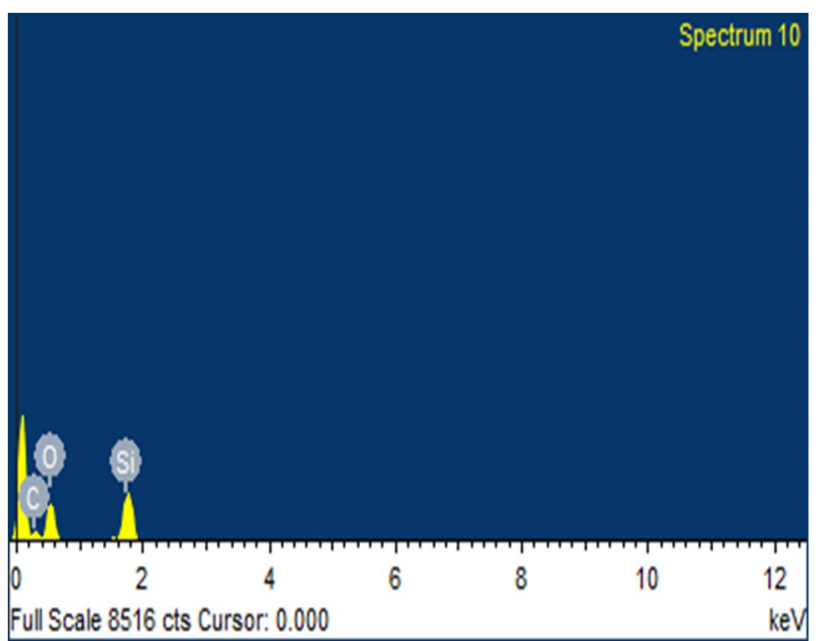

Fig. 14 (a) EDX Spectrum of Sample S (b) EDX composition of Sample S
(B)

\begin{tabular}{|c|c|c|}
\hline Element & Weight\% & Atomic\% \\
\hline $\mathrm{C}$ & 40.28 & 49.81 \\
\hline $\mathrm{O}$ & 15.51 & 29.85 \\
\hline $\mathrm{Si}$ & 1.65 & 0.92 \\
\hline Co & 42.56 & 19.42 \\
\hline Total & 100.00 & \\
\hline
\end{tabular}

reactions processes. Sample S has $60 \%$ Cobalt Sulphate and $300 \mathrm{mg}$ MWCNT. Figure $10 \mathrm{~d}$ shows the morphology of MWCNT filled with Cobalt. Figure 14a shows the EDX spectrum and Fig. 14b shows the element analysis, element percentage and atomic percentage of elements present in sample S, which contains Carbon and Cobalt nanoparticles with Oxygen and Silicon impurities.

\subsection{Microwave reflection properties of analysis 1}

The reflection loss spectra in the range of $8-13 \mathrm{GHz}$ of composites of analysis 1 are summarized in Fig. 15. From the curves, it is observed that the maximum reflection loss is observed for sample $B$ is $-30.33 \mathrm{~dB}$ at $11.8 \mathrm{GHz}$ and minimum reflection loss is observed for sample $D$ is $-7.38 \mathrm{~dB}$ at $11.8 \mathrm{GHz}$. Figure 15 shows that Sample A has $3.9 \mathrm{GHz}$ bandwidth from 8.63 to $12.53 \mathrm{GHz}$ frequency range with reflection loss less than $-10 \mathrm{~dB}$. Sample $\mathrm{B}$ has $3 \mathrm{GHz}$ bandwidth from 9 to $12 \mathrm{GHz}$ frequency range. Sample $\mathrm{C}$ has bandwidth $2.45 \mathrm{GHz}$ from 8.75 to $11.2 \mathrm{GHz}$ frequency range. Sample D has bandwidth $1.22 \mathrm{GHz}$ from 9.48 to $10.7 \mathrm{GHz}$ frequency range. The maximum bandwidth window is available for Sample A. 


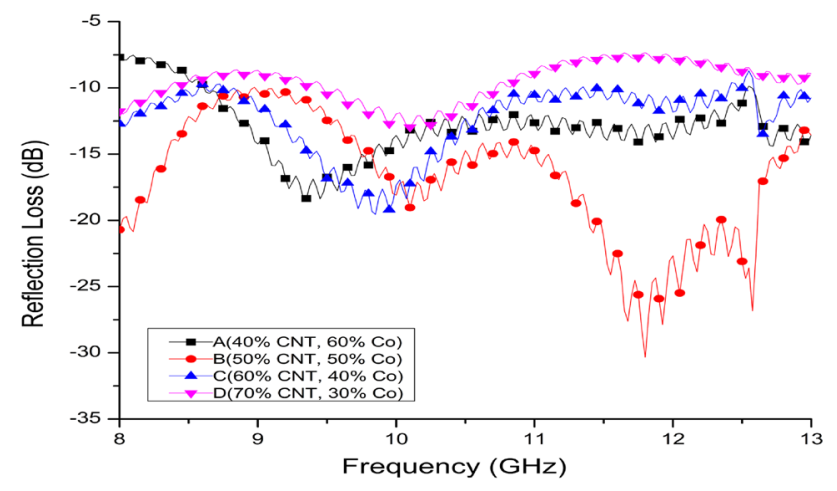

Fig. 15 Reflection Loss performance of composite with wt\% of MWCNTs and Cobalt compositions of samples (A, B, C, and D)

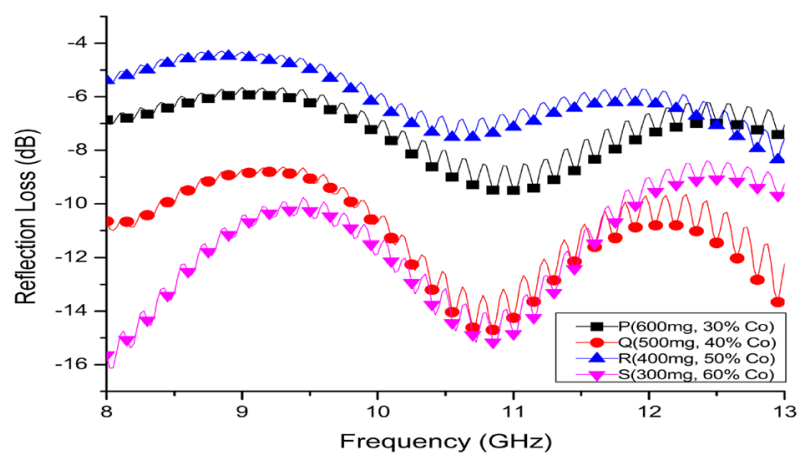

Fig. 16 Reflection Loss performance of composite with varying MWCNTs and Cobalt compositions of samples (P, Q, R, and S)

\subsection{Microwave reflection properties of analysis 2}

The reflection loss spectra in the range of $8-13 \mathrm{GHz}$ of composites of analysis 2 are summarized in Fig. 16. From the curves, it is observed that the maximum reflection loss is observed for sample $\mathrm{S}$ is $-16.15 \mathrm{~dB}$ at $8.03 \mathrm{GHz}$ and minimum reflection loss is observed for sample $\mathrm{R}$ is $-4.30 \mathrm{~dB}$ at $8.85 \mathrm{GHz}$. Figure 16 shows that Sample $\mathrm{Q}$ has $1.87 \mathrm{GHz}$ bandwidth from 9.93 to $11.8 \mathrm{GHz}$ frequency range. Sample $\mathrm{S}$ has bandwidth $2.15 \mathrm{GHz}$ from 9.63 to $11.78 \mathrm{GHz}$ frequency range. The maximum bandwidth window is available for Sample S.

\subsection{Comparison of microwave reflection properties of analysis 1 and analysis 2}

In this analysis, sample $A, B, C$ and $D$ has varying composition of MWCNTs and Cobalt Sulphate in definite proportion with respect to each other and sample $P, Q, R, S$ has varying proportion of Cobalt Sulphate only which is shown in Fig. 17. It has been observed that Sample B has maximum reflection loss of $-30.33 \mathrm{~dB}$ at $11.8 \mathrm{GHz}$ frequency

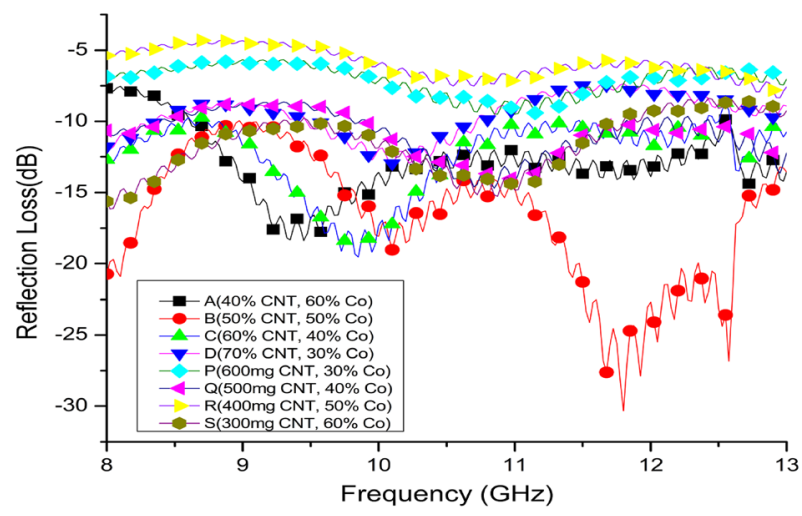

Fig. 17 Reflection Loss performance of composite with varying MWCNTs and Cobalt compositions of samples (A, B, C, D, P, Q, R, and S)

with $0.4 \mathrm{GHz}$ bandwidth window. Sample B has $50 \%$ MWCNT (dielectric material) and 50\% Cobalt Sulphate (magnetic material) composition. So, the maximum reflection occurs due to equal proportion of dielectric and magnetic properties. It has been observed that the maximum bandwidth window is available for Sample A i.e. $3.9 \mathrm{GHz}$ in the frequency range of $8-13 \mathrm{GHz}$. Sample $A$ has $40 \%$ MWCNT (dielectric material) and $60 \%$ Cobalt Sulphate (magnetic material) composition. So, the maximum window occurs due to enhanced magnetic properties over dielectric properties.

During the functionalization and filling of cobalt in MWCNTs, microstructure of MWCNTs changed prominently thus more suspending bands and imperfections were existed in Co filled MWCNTs. These suspending bands and imperfections results to more number of scattering of the electromagnetic waves and interfacial electric polarizations, which provide an important tool of microwave absorption. In Co encapsulated MWCNTs the energy levels are split (not continual), because of quantum confine effect, as stated by the Kubo theory. This effect greatly enhances the magnetic and absorbing characteristics of Co. In microwave energy range, the electrons from lower energy level absorbs the photons and jumps to a higher energy level. The MWCNTs and Polyurethane have many interfaces between their layers and outer surface. Therefore, interfacial multipoles between MWCNTs and Polyurethane contribute to the microwave absorption (Table 3).

\section{Conclusion}

In this work, Cobalt filled MWCNTs/Polyurethane composites were synthesized. The characterizations of Cobalt filled MWCNTs/Polyurethane composites were investigated by FESEM, EDX and VNA in the frequency range 
Table 3 Analysis of composite absorber in term of Reflection Loss, Thickness and Bandwidth in the range of $8-13 \mathrm{GHz}$

\begin{tabular}{lllll}
\hline Sample code & $\begin{array}{l}\text { Thickness of } \\
\text { absorber }(\mathrm{mm})\end{array}$ & $\begin{array}{l}\text { Maximum reflec- } \\
\text { tion loss }(\mathrm{dB})\end{array}$ & $\begin{array}{l}\text { Frequency for maximum } \\
\text { reflection loss }(\mathrm{GHz})\end{array}$ & Bandwidth $(\mathrm{GHz})$ \\
\hline A & 3 & -18.38 & 9.45 & 3.9 \\
B & 3 & -30.33 & 11.8 & 3 \\
$\mathrm{C}$ & 3 & -19.55 & 9.85 & 2.45 \\
$\mathrm{D}$ & 3 & -12.96 & 10.10 & 1.22 \\
$\mathrm{P}$ & 3 & -9.5 & 11 & No BW \\
$\mathrm{Q}$ & 3 & -14.7 & 10.85 & 1.87 \\
$\mathrm{R}$ & 3 & -8.35 & 12.95 & No BW \\
$\mathrm{S}$ & 3 & -16.15 & 8.03 & 2.15 \\
\hline
\end{tabular}

Table 4 Different microwave absorption characteristics of previously reported and present work

\begin{tabular}{|c|c|c|c|c|c|c|}
\hline Material (wt\%) & Matrix & $\begin{array}{l}\text { Thickness } \\
\text { of absorber } \\
(\mathrm{mm})\end{array}$ & $\begin{array}{l}\text { Maximum } \\
\text { reflection loss } \\
\text { (dB) }\end{array}$ & $\begin{array}{l}\text { Band- } \\
\text { width } \\
(\mathrm{GHz})\end{array}$ & $\begin{array}{l}\text { Frequency for maxi- } \\
\text { mum reflection loss } \\
(\mathrm{GHz})\end{array}$ & Reference \\
\hline Carbon black (50\%) & Polyethylene & 2.4 & -17.5 & 0.6 & 10.1 & [38] \\
\hline MWCNTs (2\%) & Epoxy resin & 2.24 & -25 & 3 & 10.9 & [39] \\
\hline Co/CNTs (20\%) & Epoxy resin & 1.8 & -20 & 2.8 & 8 & {$[40]$} \\
\hline Co-C/MWCNTs (25\%) & Paraffin & 2.5 & -28 & 3.6 & 10 & {$[41]$} \\
\hline Co/CNT (50\%) & Paraffin & 1 & -21.84 & 1.6 & 12.2 & {$[35]$} \\
\hline $\mathrm{CoFe}_{2} \mathrm{O}_{4} / \mathrm{FeCo} /$ Graphite (50\%) & Epoxy resin & 1.7 & -37 & 1.5 & 11.9 & {$[23]$} \\
\hline $\begin{array}{l}\text { Co/C (70\%), Ba-Hexaferrite (29\%), MWCNTs } \\
(1 \%)\end{array}$ & Paraffin & 2.5 & -26 & 4.2 & 12.4 & {$[25]$} \\
\hline $\begin{array}{l}\text { Graphene oxide/CNTs } / \mathrm{Co}_{x} \mathrm{Fe}_{3-\mathrm{x}} \mathrm{O}_{4,} \mathrm{x}=0.6 \\
(80.99 \%)\end{array}$ & Epoxy resin & 8.50 & -18 & 1 & 12 & {$[22]$} \\
\hline MWCNTs (20\%), $\mathrm{CoSO}_{4}(30 \%)$ & Polyurethane & 3 & -18.38 & 3.9 & 9.45 & This work \\
\hline MWCNTs (25\%), $\mathrm{CoSO}_{4}(25 \%)$ & Polyurethane & 3 & -30.33 & 3 & 11.8 & This work \\
\hline
\end{tabular}

of $8-13 \mathrm{GHz}$. The maximum reflection loss achieved was $-30.22 \mathrm{~dB}$ at $11.8 \mathrm{GHz}$ with $3 \mathrm{~mm}$ thickness and $0.4 \mathrm{GHz}$ bandwidth at 50\% MWCNT and 50\% Cobalt Sulphate composition. The maximum bandwidth was $3.9 \mathrm{GHz}$ with $3 \mathrm{~mm}$ thickness at 40\% MWCNT and 60\% Cobalt Sulphate composition. The reflection loss enhancement of the Co filled MWCNTs/Polyurethane composites owing to the involvement of both Co and MWCNTs, which provides combine effect of dielectric losses, magnetic losses, improved matched impedance and larger microwave attenuation properties of the absorber. Due to the interfacial multipoles between Cobalt filled MWCNTs and Polyurethane, the microwave absorption of Cobalt filled MWCNTs/Polyurethane composites is enhanced. It is evident from the results that these Cobalt filled MWCNTs composites studied as promising radar absorbing materials (Table 4).

Declarations Conflicts of interest The authors state that they have no conflicts of interest.

\section{References}

1. Lee SE, Kang JH, Kim CG (2006) Fabrication and design of multilayered radar absorbing structures of MWNT-filled glass/epoxy plain-weave composites. Compos Struct 76:397-405. https:// doi.org/10.1016/j.compstruct.2005.11.036

2. Liu Z, Bai G, Huang Y, Li F, Ma Y, Guo T, He X, Lin X, Gao H, Chen $Y$ (2007) Microwave absorption of single-walled carbon nanotubes/soluble cross-linked polyurethane composites. J Phys Chem C 111:13696-13700. https://doi.org/10.1021/jp0731396

3. Saini P, Choudhary V, Vijayan N, Kotnala RK (2012) Improved electromagnetic interference shielding response of poly(aniline)coated fabrics containing dielectric and magnetic nanoparticles. J Phys Chem C 116:13403-13412. https://doi.org/10.1021/jp302 $131 \mathrm{w}$

4. Singh BP, Choudhary V, Saini P, Mathur RB (2012) Designing of epoxy composites reinforced with carbon nanotubes grown carbon fiber fabric for improved electromagnetic interference shielding. AIP Adv 2:022151. https://doi.org/10.1063/1.4730043

5. Nam IW, Lee HK, Jang JH (2011) Electromagnetic interference shielding/absorbing characteristics of CNT-embedded epoxy composites. Compos Part A Appl Sci Manuf 42:1110-1118. https ://doi.org/10.1016/j.compositesa.2011.04.016

6. Singh BP, Prasanta, Choudhary V, Saini P, Pande S, Singh VN, Mathur RB (2013) Enhanced microwave shielding and mechanical properties of high loading MWCNT-epoxy composites. 
J Nanoparticle Res 15:1-12. https://doi.org/10.1007/s1105 1-013-1554-0

7. Saini P, Choudhary V, Singh BP, Mathur RB, Dhawan SK (2011) Enhanced microwave absorption behavior of polyaniline-CNT/ polystyrene blend in 12.4-18.0 GHz range. Synth Met 161:15221526. https://doi.org/10.1016/j.synthmet.2011.04.033

8. Singh BP, Saini K, Choudhary V, Teotia S, Pande S, Saini P, Mathur RB (2014) Effect of length of carbon nanotubes on electromagnetic interference shielding and mechanical properties of their reinforced epoxy composites. J Nanoparticle Res 16:2161. https ://doi.org/10.1007/s11051-013-2161-9

9. Singh BP, Prabha, Saini P, Gupta T, Garg P, Kumar G, Pande I, Pande S, Seth RK, Dhawan SK, Mathur RB (2011) Designing of multiwalled carbon nanotubes reinforced low density polyethylene nanocomposites for suppression of electromagnetic radiation. J Nanoparticle Res 13:7065-7074. https://doi.org/10.1007/ s11051-011-0619-1

10. Pande S, Singh BP, Mathur RB (2014) Processing and Properties of Carbon Nanotube/Polycarbonate Composites. Polym Nanotub Nanocomposites Synth Prop Appl Second Ed 9781118945926:333-364. https://doi.org/10.1002/9781118945 964.ch9

11. Yusuf JY, Soleimani H, Noorhana yahya, Sanusi YK, Adebayo LL, Sikiru S, Wahaab FA (2020) Recent advances and prospect of cobalt based microwave absorbing materials. Ceram Int 46:26466-26485. https://doi.org/10.1016/j.ceram int.2020.07.244

12. Kumar $P$, Narayan Maiti U, Sikdar A, Kumar Das T, Kumar A, Sudarsan V (2019) Recent Advances in Polymer and Polymer Composites for Electromagnetic Interference Shielding: Review and Future Prospects. Polym Rev 59:687-738. https:// doi.org/10.1080/15583724.2019.1625058

13. Panwar R, Lee JR (2019) Recent advances in thin and broadband layered microwave absorbing and shielding structures for commercial and defense applications. Funct Compos Struct 1:032001. https://doi.org/10.1088/2631-6331/ab2863

14. Setua DK, Mordina B, Srivastava AK, Roy D, Eswara Prasad N (2020) Carbon nanofibers-reinforced polymer nanocomposites as efficient microwave absorber. In: Fiber reinforced nanocomposites: fundamentals and applications. Elsevier, Amsterdam, pp 395-430

15. Raveendran A, Sebastian MT, Raman S (2019) Applications of Microwave Materials: A Review. J Electron Mater 48:2601-2634. https://doi.org/10.1007/s11664-019-07049-1

16. Sun J, Wang L, Yang Q, Shen Y, Zhang X (2020) Preparation of copper-cobalt-nickel ferrite/graphene oxide/polyaniline composite and its applications in microwave absorption coating. Prog Org Coatings 141:105552. https://doi.org/10.1016/j.porgc oat.2020.105552

17. Wu Q, Jin H, Zhang B, Huo S, Yang S, Su X, Wang J (2020) Facile synthesis of cobalt-doped porous composites with amorphous carbon/Zn shell for high-performance microwave absorption. Nanomaterials 10:1-14. https://doi.org/10.3390/nano10020330

18. Zhao P, Wang H, Wang G (2019) Enhanced electromagnetic absorption properties of commercial Ni/MWCNTs composites by adjusting dielectric properties. Front Chem 8:97. https://doi. org/10.3389/fchem.2020.00097

19. Chen W, Zheng X, He X, Su Y, Wang J, Yang J, Chen S, Zheng Z (2020) Achieving full effective microwave absorption in $X$ band by double-layered design of glass fiber epoxy composites containing MWCNTs and $\mathrm{Fe}_{3} \mathrm{O}_{4}$ NPs. Polym Test 86:106448. https:// doi.org/10.1016/j.polymertesting.2020.106448

20. Li Y, Zheng W, Zhang A, Wang D, Kong J (2020) Effect of nickel shell thickness of $\mathrm{Ni}$-microsphere on microwave absorption properties of Ni-microsphere@MWCNTs hybrids. J Magn Magn
Mater 513:167218. https://doi.org/10.1016/j.jmmm.2020.16721 8

21. Guan ZJ, Jiang JT, Yan SJ, Sun YM, Zhen L (2020) Sandwich-like cobalt/reduced graphene oxide/cobalt composite structure presenting synergetic electromagnetic loss effect. J Colloid Interface Sci 561:687-695. https://doi.org/10.1016/j.jcis.2019.11.045

22. Wu M, Qi X, Xie R, Bai Z, Qin S, Zhong W, Deng C (2020) Graphene oxide/carbon nanotubes $/ \mathrm{Co}_{x} \mathrm{Fe}_{3-\mathrm{x}} \mathrm{O}_{4}$ ternary nanocomposites: Controllable synthesis and their excellent microwave absorption capabilities. J Alloys Compd 813:151996. https://doi. org/10.1016/j.jallcom.2019.151996

23. Su X, Wang J, Zhang X, Huo S, Chen W, Dai W, Zhang B (2020) One-step preparation of $\mathrm{CoFe}_{2} \mathrm{O}_{4} / \mathrm{FeCo} /$ graphite nanosheets hybrid composites with tunable microwave absorption performance. Ceram Int 46:12353-12363. https://doi.org/10.1016/j. ceramint.2020.01.286

24. Xiang Z, Deng B, Huang C, Liu Z, Song Y, Lu W (2020) Rational design of hollow nanosphere $\gamma-\mathrm{Fe}_{2} \mathrm{O}_{3} / \mathrm{MWCNTs}$ composites with enhanced electromagnetic wave absorption. J Alloys Compd 822:153570. https://doi.org/10.1016/j.jallcom.2019.153570

25. Peibo L, Yize S, Akinay Y (2020) The influence of MWCNTs on microwave absorption properties of $\mathrm{Co} / \mathrm{C}$ and $\mathrm{Ba}$-Hexaferrite hybrid nanocomposites. Synth Met 263:116369. https://doi. org/10.1016/j.synthmet.2020.116369

26. Lang J, Yan X, Xue Q (2011) Facile preparation and electrochemical characterization of cobalt oxide/multi-walled carbon nanotube composites for supercapacitors. J Power Sources 196:7841-7846. https://doi.org/10.1016/j.jpowsour.2011.04.010

27. Hao Z, Liu QF, Wang JB (2010) Coating carbon nanotubes with ferrites using an improved co-precipitation method. J Compos Mater 44:389-395. https://doi.org/10.1177/0021998309347576

28. Liu Y, Jiang W, Li S, Li F (2009) Electrostatic self-assembly of $\mathrm{Fe}_{3} \mathrm{O}_{4}$ nanoparticles on carbon nanotubes. Appl Surf Sci 255:79998002. https://doi.org/10.1016/j.apsusc.2009.05.002

29. Wang X, Zhao Z, Qu J, Wang Z, Qiu J (2010) Fabrication and characterization of magnetic $\mathrm{Fe}_{3} \mathrm{O}_{4}$-CNT composites. J Phys Chem Solids 71:673-676. https://doi.org/10.1016/j.jpcs.2009.12.063

30. Dong CK, Li X, Zhang Y, Qi JY, Yuan YF (2009) $\mathrm{Fe}_{3} \mathrm{O}_{4}$ nanoparticles decorated multi-walled carbon nanotubes and their sorption properties. Chem Res Chinese Univ 25:936-940

31. Song S, Yang H, Rao R, Liu H, Zhang A (2010) High catalytic activity and selectivity for hydroxylation of benzene to phenol over multi-walled carbon nanotubes supported $\mathrm{Fe}_{3} \mathrm{O}_{4}$ catalyst. Appl Catal A Gen 375:265-271. https://doi.org/10.1016/j.apcat a.2010.01.008

32. Rosca ID, Watari F, Uo M, Akasaka T (2005) Oxidation of multiwalled carbon nanotubes by nitric acid. Carbon N Y 43:31243131. https://doi.org/10.1016/j.carbon.2005.06.019

33. Xiu-juan FAN, Xin LI (2012) Preparation and magnetic property of multiwalled carbon nanotubes decorated by $\mathrm{Fe}_{3} \mathrm{O}_{4}$ nanoparticles. New Carbon Mater 27:111-116. https://doi.org/10.1016/ S1872-5805(12)60007-9

34. Zhao DL, Zhang JM, Li X, Shen ZM (2010) Electromagnetic and microwave absorbing properties of Co-filled carbon nanotubes. J Alloys Compd 505:712-716. https://doi.org/10.1016/j.jallc om.2010.06.122

35. Verma M, Chauhan SS, Dhawan SK, Choudhary V (2017) Graphene nanoplatelets/carbon nanotubes/polyurethane composites as efficient shield against electromagnetic polluting radiations. Compos Part B Eng 120:118-127. https://doi. org/10.1016/j.compositesb.2017.03.068

36. Gupta TK, Singh BP, Dhakate SR, Singh VN, Mathur RB (2013) Improved nanoindentation and microwave shielding properties of modified MWCNT reinforced polyurethane composites. J Mater Chem A 1:9138-9149. https://doi.org/10.1039/c3ta1 $1611 \mathrm{e}$ 
37. Gupta TK, Singh BP, Teotia S, Katyal V, Dhakate SR, Mathur RB (2013) Designing of multiwalled carbon nanotubes reinforced polyurethane composites as electromagnetic interference shielding materials. J Polym Res 20:32-35. https://doi. org/10.1007/s10965-013-0169-6

38. Ansari A, Akhtar MJ (2018) High Porous Carbon Black Based Flexible Nanocomposite as Efficient Absorber for X-band Applications. Mater Res Express Accept 5:0-31

39. Kim JB, Lee SK, Kim CG (2008) Comparison study on the effect of carbon nano materials for single-layer microwave absorbers in X-band. Compos Sci Technol 68:2909-2916. https://doi. org/10.1016/j.compscitech.2007.10.035

40. Wu N, Lv H, Liu J, Liu Y, Wang S, Liu W (2016) Improved electromagnetic wave absorption of Co nanoparticles decorated carbon nanotubes derived from synergistic magnetic and dielectric losses. Phys Chem Chem Phys 18:31542-31550. https:// doi.org/10.1039/c6cp06066h

41. Shu R, Li W, Wu Y, Zhang J, Zhang G (2019) Nitrogen-doped Co-C/MWCNTs nanocomposites derived from bimetallic metalorganic frameworks for electromagnetic wave absorption in the X-band. Chem Eng J 362:513-524. https://doi.org/10.1016/j. cej.2019.01.090

Publisher's Note Springer Nature remains neutral with regard to jurisdictional claims in published maps and institutional affiliations. 